\title{
New Factors for Protoplast-Callose-Fiber Formation in Salt-Tolerant Mangrove Plants, Avicennia alba and Bruguiera sexangula and Analysis of Fiber Substructures
}

\author{
Asami Kurita-Tashiro ${ }^{1}$, Noriko Hayashi ${ }^{2}$, Tomoya Oyanagi ${ }^{1} \&$ Hamako Sasamoto ${ }^{3,4}$ \\ ${ }^{1}$ Graduate School of Environment and Information Sciences, Yokohama National University, Yokohama, Japan \\ ${ }^{2}$ Forestry and Forest Products Research Institute, Tsukuba, Ibaraki, Japan \\ ${ }^{3}$ Faculty of Environment and Information Sciences, Yokohama National University, Yokohama, Japan \\ ${ }^{4}$ Department of International Environmental and Agricultural Sciences, Tokyo University of Agriculture and \\ Technology, Fuchu, Tokyo, Japan \\ Correspondence: Hamako Sasamoto, Department of International Environmental and Agricultural Sciences, \\ Tokyo University of Agriculture and Technology, Fuchu, Tokyo, 183-8509, Japan. Tel: 81-42-367-5625. E-mail: \\ sasamoto@ynu.ac.jp
}

Received: March 12, 2020

Accepted: April 5, $2020 \quad$ Online Published: May 2, 2020

doi:10.5539/jps.v9n2p1

URL: https://doi.org/10.5539/jps.v9n2p1

\begin{abstract}
Elongated and spiral $\beta$-1,3-glucan (callose) fibers were obtained by new factors from protoplasts cultured in liquid medium from suspension cultured cells of two salt-tolerant mangrove species; Avicennia alba and Bruguiera sexangula. Differences in salt factor for protoplast-fiber formation were compared with those of the callose fibers developed from protoplasts of non-mangrove tree plants, Larix leptolepis and Betula platyphylla, which high concentrations of divalent cations, $\mathrm{Mg}^{2+}(50 \mathrm{mM})$ or $\mathrm{Ca}^{2+}(100 \mathrm{mM})$, were stimulatory. In the halophilic A. alba protoplasts, whose cell division was stimulated by up to $400 \mathrm{mM} \mathrm{NaCl}$, addition of $\mathrm{Mg}^{2+}, \mathrm{Ca}^{2+}$, $\mathrm{K}^{+}$ions inhibited protoplast-fiber formation. In B. sexangula, protoplast-fibers were rapidly and efficiently formed only by another new factor, electric cell fusion treatment of protoplasts. Spiral fibers developed from mangrove protoplasts were detected under an inverted microscope, and their specific blue-green color for callose after staining with Aniline Blue dye was detected under a fluorescence microscope. Enzymatic certification of callose was further performed with laminarinase, specific for callose, in comparison with cellulase CBH1, specific for cellulose. Differences in sub-structures, fibrils and sub-fibrils of two mangrove protoplast-fibers were analyzed using laser confocal scanning microscopy, atomic force microscopy and image $J$ analysis. Tube-like fine structure was observed using transmission electron microscopy in single protoplast-fiber of $B$. sexangula selected with a micromanipulator.
\end{abstract}

Keywords: AFM, glucans, LCSM, protoplast-fiber, salts, TEM

\section{Introduction}

Sasamoto et al. (2003) reported novel protoplast-fiber formation using protoplast cultures of Betula platyphylla leaves and embryogenic cells of a conifer, Larix leptolepis, in liquid medium containing high concentrations of $\mathrm{CaCl}_{2}(100 \mathrm{mM})$, and $\mathrm{MgCl}_{2}(50 \mathrm{mM})$, respectively. A spiral elongated fiber developed from the surface of a spherically enlarged protoplast. These findings suggested the importance of divalent cations in protoplast-fiber formation. The spiral protoplast-fibers could be observed under an inverted microscope after two weeks to more than one month of protoplast culture. They were stained with Aniline Blue dye which showed a $\beta-1,3$-glucan (callose) component. Helical structure was shown in transmission electron microscopy (TEM) (Sasamoto et al., 2003). Fukumoto et al. (2005) certified callose component for the Larix protoplast-fiber by using specific enzymes for callose degradation (laminarinase), and no degradation for cellulose (Cellulase CBH1, Hayashi et al., 1997 a, b). Sub-structures of Larix protoplast-fibers were clarified by atomic force microscopy (AFM) and image $\mathbf{J}$ analysis (Fukumoto et al. 2005). Sub-structures of Betula protoplast-fibers were studied, though the protoplast culture methods were wrongly described (Seyama et al., 2008). The protoplast-fibers were studied further using laser confocal scanning microscopy (LCSM) with Alexafluor 488 phalloidin staining, and using single cell TEM to visualize the site of protoplat-fiber elongation from a single Larix protoplast selected with a 
micromanipulator (Oyanagi et al., 2014). Mechanical properties of single elongated protoplast-fibers of Larix and Betula were measured by a unique tensile test using two micromanipulators under an inverted microscope, and future development of an alkali-labile nanomachine at a cellular level was discussed (Oyanagi et al., 2014; 2017).

On the other hand, different effects of four salts, $\mathrm{NaCl}, \mathrm{KCl}, \mathrm{MgCl}_{2}$ and $\mathrm{CaCl}_{2}$, were investigated on the growth (cell division) of protoplasts of salt-tolerant or halophilic mangrove tree plants, e.g. suspension-cultured cells of Bruguiera sexangula (Fukumoto et al., 2004), and Avicennia alba (Hasegawa et al., 2013). Effects of four salts and medium pHs were compared with those on protoplasts of poplar leaves and tobacco suspension-cultured cells (Fukumoto et al., 2004). The rate of protoplast-fiber formation of poplar and tobacco by addition of four salts was low (Fukumoto 2006). However, to our knowledge, protoplast-fiber formation in mangrove tree plants cells has not been reported.

Here we examined the effects of five salts (including $\mathrm{MgSO}_{4}$ ) in the protoplast culture medium on the protoplast-fiber formation and cell division of halophilic mangrove species, A. alba. In the salt-tolerant mangrove species, $B$. sexangula, effects of electric treatments, which were effective for cell fusion of protoplasts of broad-leaved trees, Populus alba, Betula platyphylla and Alnus firma (Sasamoto et al., 2000; Wakita et al., 2005), were studied on the rapid formation of protoplast-fibers. The callose component was certified enzymatically, and sub-structures of the fibers were analyzed using LCSM and AFM with image J analysis. The fine structure of a single fiber of $B$. sexangula selected with a micromanipulator was analyzed using TEM.

\section{Method}

\subsection{Suspension Culture}

A suspension culture of Avicennia alba was induced from cotyledons (Hayashi et al. 2009) and sub-cultured at 3to 4 -week intervals in a modified amino acid (mAA) basal medium containing 3\% sucrose, $2 \mu \mathrm{M}$ each of 2,4-dichlorophenoxyacetic acid (2,4-D) and thidiazuron (TDZ) as described previously (Hasegawa et al., 2011, 2013). The leaf-derived suspension culture of Bruguiera sexangula (Mimura et al., 1997; Kura-Hotta et al., 2001) was sub-cultured at about 3-week intervals in mAA basal medium containing 3\% sucrose, $0.02 \mu \mathrm{M}$ of 2,4-D and $2 \mu \mathrm{M}$ of N-(2-chlorp-4-pyridyl)-N'-phenylurea (CPPU). Three-week-old suspension cells were used for protoplast isolation. The mAA basal medium contained various elements as the major salt components $(0.2 \mathrm{mM}$ $\mathrm{Na}, 21.25 \mathrm{mM} \mathrm{K}, 1.5 \mathrm{mM} \mathrm{Mg}, 3 \mathrm{mM} \mathrm{Ca}, 26 \mathrm{mM} \mathrm{Cl}$ ). All cultures were incubated at $30^{\circ} \mathrm{C}$ on a rotary shaker at a speed of $100 \mathrm{rpm}$ in the dark.

\subsection{Protoplast Isolation}

Protoplasts of A. alba were isolated in 1\% each of Cellulase RS (Yakult) and Driselase 20 (Kyowa Hakko Kogyo) in 1.2 M sorbitol solution (Hasegawa et al., 2011, 2013) and protoplasts of B. sexangula were isolated with $1 \%$ Cellulase RS and $0.25 \%$ Pectolyase Y-23 (Seishin) in 0.6 M mannitol solution (Fukumoto et al., 2004). Protoplasts were purified by filtration through nylon mesh $(95$ or $40 \mu \mathrm{m})$ and were washed with osmoticum solution three times by centrifugation at $100 \mathrm{~g} 4 \mathrm{~min}$.

\subsection{Electric Treatment of B. sexangula Protoplasts}

Electric treatment of $B$. sexangula was performed directly after protoplast isolation or after storage for one day in $0.6 \mathrm{M}$ mannitol solution at room temperature. Protoplasts at $10^{6} \mathrm{~mL}^{-1}$ density in $0.6 \mathrm{M}$ mannitol solution was mixed with an equal volume of $0.5 \mathrm{M}$ mannitol solution containing $5 \mathrm{mM} \mathrm{CaCl}_{2}$ (in a fusion buffer). After 150 $\mathrm{V} / \mathrm{cm}$ AC voltage was applied for 20-30 sec to make a pearl chain, DC voltage was applied at $2 \mathrm{KV} / \mathrm{cm}, 99 \mu \mathrm{sec}$ using the Electro cell fusion generator (NEPA GENE LF101) with a $2 \mathrm{~mm}$ gap electrode using $150 \mu \mathrm{L}$ protoplast suspension. The condition was the same as that for electric cell fusion of poplar protoplasts (Sasamoto et al., 2000; Wakita et al., 2005). AC or DC treatment alone was also applied. All the procedures were performed under an inverted microscope under a sterile condition (AS ONE Simplified clean booth, pure space).

\subsection{Protoplast Culture}

The protoplasts were cultured in 96-well culture plates (Falcon No.3075). A $5 \mu \mathrm{L}$ isolated protoplast suspension in osmoticum solution was put in $50 \mu \mathrm{L}$ liquid medium in each well. Ultra-pure water $(100 \mu \mathrm{L})$ was supplied between wells. They were incubated at $30^{\circ} \mathrm{C}$ in a humid incubator $\left(\mathrm{CO}_{2}\right.$ incubator, Astec APC 30D/CL-30) without the supply of $\mathrm{CO}_{2}$ gas. Protoplasts of $A$. alba were cultured in mAA basal medium containing $2 \mu \mathrm{M}$ each of 2,4-D and TDZ, 3\% sucrose, 1.2 $\mathrm{M}$ sorbitol solution. (Hasegawa et al., 2011, 2013). The medium $\mathrm{pH}$ was adjusted to 6.2-6.3 with $\mathrm{NaOH}$. $\mathrm{NaCl}, \mathrm{KCl}, \mathrm{MgCl}_{2}, \mathrm{MgSO}_{4}$ and $\mathrm{CaCl}_{2}$ were added at concentrations of $0,10,25$, $50,100,200,300$ or $400 \mathrm{mM}$. Protoplasts of $B$. sexangula with or without electric treatment were cultured in Murashige and Skoog's (MS, Murashige \& Skoog, 1962) basal medium containing 3\% sucrose, 0.3 M mannitol 
and with or without $0.02 \mu \mathrm{M}$ 2,4-D, $2 \mu \mathrm{M}$ CPPU and $25 \mathrm{mM}$ of $\mathrm{MgCl}_{2}$ (Fukumoto et al., 2004). The MS basal medium contained the same concentrations of elements, $\mathrm{Na}, \mathrm{K}, \mathrm{Mg}, \mathrm{Ca}$ of the mAA basal medium except for 6 $\mathrm{mM} \mathrm{Cl}$. The medium $\mathrm{pH}$ was adjusted to 5.7-5.8 with $\mathrm{KOH}$. Protoplast density was adjusted to $5 \times 10^{4} \mathrm{~mL}^{-1}$. Numbers of divided cells and fibers were counted under an inverted microscope (Olympus CK40 or IX71) after 22-46 days of culture ( $A$ alba), or after 1-10 days of culture (B. sexangula). Data were averaged with standard error (SE) from numbers of 2-15 wells.

\subsection{Observation of Fibers}

All procedures were performed as described previously for protoplast-fibers of a conifer, Larix leptolepis (Fukumoto et al., 2005; Oyanagi et al., 2014).

\subsubsection{Observation of Fibers after Aniline Blue Staining}

Fibers were observed first and the numbers per well were counted under an inverted microscope. Then, fibers were stained with Aniline Blue solution $(0.5 \%, \mathrm{pH} 8.5)$, which was added to the cultured well at a final concentration of $0.05 \%$ (Sasamoto et al., 2003; Fukumoto et al., 2005). Fibers (after micromanipulation) were observed using a fluorescence inverted microscope (Olympus IX71, UV filter U-MWU2) and laser confocal scanning microscope (Nikon C1, Differential interference contrast (DIC) and fluorescence inverted microscope, Nikon).

\subsubsection{Micromanipulation}

Fibers and fiber-forming protoplasts were selected using micromanipulators (Narishige MM-89, Narishige-Nikon MM-188) with a microinjector (IM-188) under an inverted microscope (Olympus IX-71, CK-40). Micropipettes for picking up were made from a glass capillary (10 $\mu \mathrm{L}$, Drummond) using a micropipette puller (PB-7, Narishige), and were bent with a micro-burner (Pen burner, Prince) as previously described (Ogita et al., 1999; Sasamoto et al., 2000; Oyanagi et al., 2014).

\subsubsection{Enzymatic Treatment of Fibers}

Enzymatic treatment was performed as described for Larix fiber (Fukumoto et al. 2005). Fibers were treated with laminarinase (Sigma), $\beta$-1,4-glucan cellobiohydrolase I (CBH-1, Hayashi et al., 1997 a, b) and Meicelase (crude cellulase from Trichoderma viride). Bacterial (Acetobacter xylinum) cellulose and cotton cellulose were provided as a control. After $24 \mathrm{hr}$ of incubation in a 96-well culture plate, degradation was observed under an inverted microscope. Finally, remaining callose fibers were checked by staining with Aniline Blue, and observed under a fluorescence inverted microscope with a UV filter.

\subsubsection{AFM}

Using a micromanipulator, each fiber was put on a piece of isopore ${ }^{\mathrm{TM}}$ Membrane filter (Milipore) taped on a cover glass with cut double-sided tape and dried. The fiber-structures were observed under an atomic force microscope (Nanoscope III; Digital Instruments) equipped with a scanner with a $10 \mu \mathrm{m}$ range (E-scanner).

\subsubsection{Image J}

To predict the sub-structures of the fibers, LCSM and AFM images were analyzed by using the Image J program, Image J (NIH, Rasband, 1997-2016). Plot profile data were obtained from the line indicated in figures in the results. Peak distance were calculated by use of Image J, and averaged as a diameter of the fibrils or sub-fibrils.

\subsubsection{TEM}

Using a micromanipulator, a single fiber-forming protoplast was transferred to a droplet of microbeads of agarose (6-8 $\mu \mathrm{L}$, low gelling temperature type \#7 A4018, Sigma, dissolved in the medium for protoplast culture) before solidification at room temperature in a well of a 4-well plastic plate (Nunc). The beads were fixed with cold $2 \%$ glutaraldehyde solution for $1 \mathrm{hr}$ at $4^{\circ} \mathrm{C}$. They were washed with $0.1 \mathrm{M}$ phosphate buffer (pH7.0), and transferred to a microtube with a small spatula. They were treated with $1 \%$ osmium tetroxide at $4^{\circ} \mathrm{C}$, washed with ultra pure water several times by centrifugation, successively dehydrated with ethanol and acetone series, and embedded in LRwhite resin. Ultrathin sections were put on a grid with thin formvar film, then stained with $1 \%$ uranyl acetate and $\mathrm{Pb}$-citrate and examined using a JEM-2000EX (JEOL) transmission electron microscope operated at $200 \mathrm{kV}$ (Hayashi et al., 1997a,b; Oyanagi et al., 2014).

\section{Results and Discussion}

\subsection{Effects of Salts and pH on Cell Division and Fiber Formation of Mangrove Protoplasts}

Figure 1 shows the numbers of divided cells (Figure 1a, modified from Hasegawa et al., 2013) and numbers of fibers (Figure 1b) developed after about 1.5 months-culture of protoplasts of A. alba. As for cell division, the 
halophilic nature to $\mathrm{NaCl}$ was prominent up to $400 \mathrm{mM}$, and highly tolerant to $\mathrm{MgCl}_{2}$, and $\mathrm{MgSO}_{4}$ up to the concentrations of $300 \mathrm{mM}$. In contrast, $\mathrm{CaCl}_{2}$ was inhibitory even at the lowest concentration tested. Protoplast-fiber formation was inhibited by the addition of all salts tested, except for low $10 \mathrm{mM} \mathrm{NaCl}$ (Figure 1b). $\mathrm{CaCl}_{2}$ inhibited both cell division and fiber formation in A. alba. Without additional salts, thick fibers (20 $\mu \mathrm{m}$ diameter) were observed under an inverted microscope (Figure 2a). After 22 days of culture, lower numbers of fibers were counted and no stimulation by $\mathrm{NaCl}$ was observed (data not shown). In A. alba protoplast cultured with high concentrations of $\mathrm{Ca}^{2+}$ ions, increase in the diameter of large spherical protoplasts (which resembled the fiber-forming spherical protoplasts of Betula) was reported (Hasegawa et al., 2013). However, no protoplast-fibers were observed. Inhibition of fiber formation of $A$. alba by divalent cations is a phenomenon different from that previously reported in protoplast-callose-fibers developed from protoplasts of non-mangrove tree plants, Larix and Betula which required a high concentration of divalent cations, $\mathrm{Mg}^{2+}(50 \mathrm{mM})$ and $\mathrm{Ca}^{2+}$ (100 mM), respectively (Sasamoto et al., 2003; Fukumoto et al., 2005).
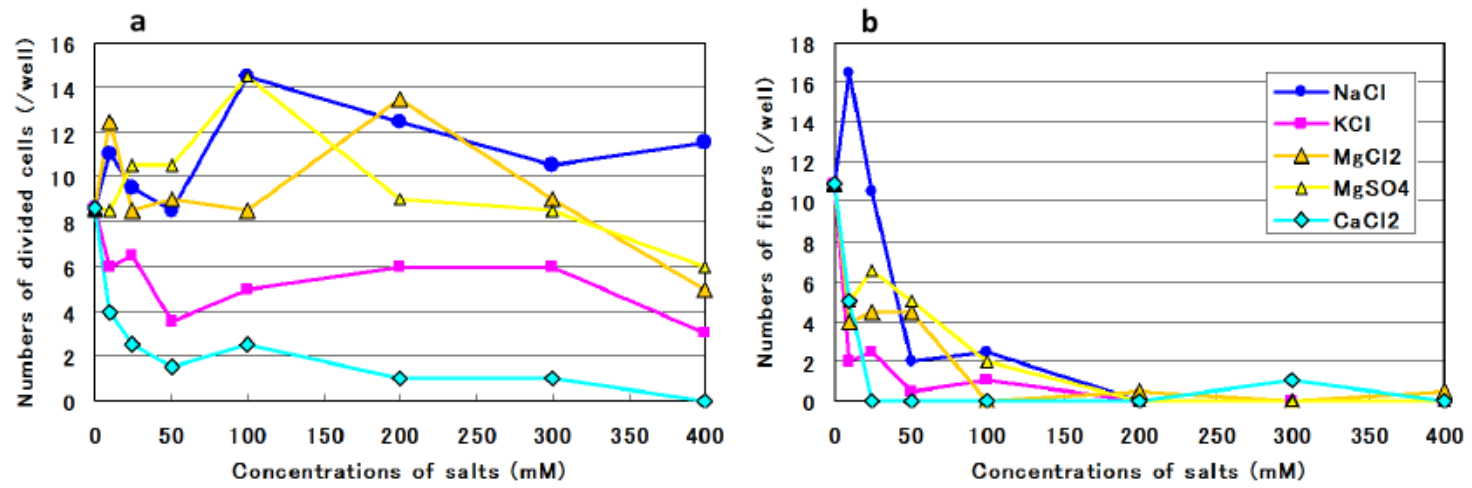

Figure 1. Effects of five salts on cell division (a) and protoplast-fiber formation (b) after 1.5 months of protoplast culture of Avicennia alba. Basal medium was mAA medium containing $2 \mu \mathrm{M}$ each of 2,4-D and TDZ, 3\% sucrose and 1.2 M sorbitol. Numbers were counted under an inverted microscope. Numbers were 8.6 +-0.65 (a) and $10.9+-1.2$ (b) at zero control. Fig. 1a was modified from Hasegawa et al., 2013

Mechanical properties of single protoplast-fibers were determined using the unique tensile test under an inverted microscope (Oyanagi et al. 2017). Similar Young's modulus was obtained for the Larix fiber (10 $\mu \mathrm{m}$ diameter), and for Betula fiber (20-25 $\mu \mathrm{m}$ diameter) with or without high $\mathrm{Ca}^{2+}$ ions during the test. Such divalent cations might be needed only during the culture for elongation of protoplast-fibers.

Effects of salt and medium $\mathrm{pH}$ on cell division in protoplast cultures of the salt-tolerant mangrove plant, $B$. sexangula were compared with those of non-mangrove tree plant Populus alba (Fukumoto et al., 2004). In B. sexangula protoplasts cultured at the usual $\mathrm{pH}$ of 5.7 , were tolerant to $\mathrm{NaCl}$ up to $25 \mathrm{mM}$, cell division was slightly stimulated by $25 \mathrm{mM} \mathrm{MgCl} 2$, but strongly stimulated by $10-25 \mathrm{mM} \mathrm{CaCl}_{2}$. At the medium $\mathrm{pH} 6.2$, which was the $\mathrm{pH}$ in mAA basal medium of the original suspension culture of $B$. sexangula, stimulation by $25 \mathrm{mM}$ $\mathrm{NaCl}$ and strong inhibition of cell division by $\mathrm{CaCl}_{2}$ was observed (Fukumoto et al. 2004). However, no fiber formation was observed at all salt and $\mathrm{pH}$ conditions including high concentrations of divalent cation salts (Fukumoto, 2006).

Betula protoplasts can form fibers in a strongly acidic medium (pH 3.5). However, in Betula protoplasts, colony formation was not inhibited in an acidic medium when optimal hormonal conditions were used (Sasamoto et al., 2003; Seyama et al., 2008 correctly without the supply of $\mathrm{CO}_{2}$ gas). In contrast, in poplar protoplast cultures, all salts at acidic pHs inhibit cell division in an $\mathrm{Cl}^{-}$ion-dependent manner, and no fiber formation was observed (Fukumoto et al., 2004; Fukumoto 2006).

Protoplast-fibers formed in protoplast cultures of not only tree species, but also herbaceous plants, in the presence of high concentrations of divalent cations, e.g., suspension-cultured cells of tobacco BY-2 (low efficient at $75 \mathrm{mM} \mathrm{MgCl}{ }_{2}$ ) and Vinca rosea (highly efficient at 50-100 $\mathrm{mM} \mathrm{CaCl} 2$ ) (Fukumoto, 2006). Recently, the effects of different salts on cell division and fiber formation in leaf protoplasts of Arabidopsis thaliana were studied (Oyanagi et al. 2017; Sasamoto et al., in preparation). Increase in the numbers of protoplast-fibers by an inhibitor of cell wall formation, in addition to high $\mathrm{CaCl}_{2}$ and acidic $\mathrm{pH}$, was reported in suspension cells of 
tobacco BY-2 and Arabidopsis (Tagawa \& Kondo, 2018).

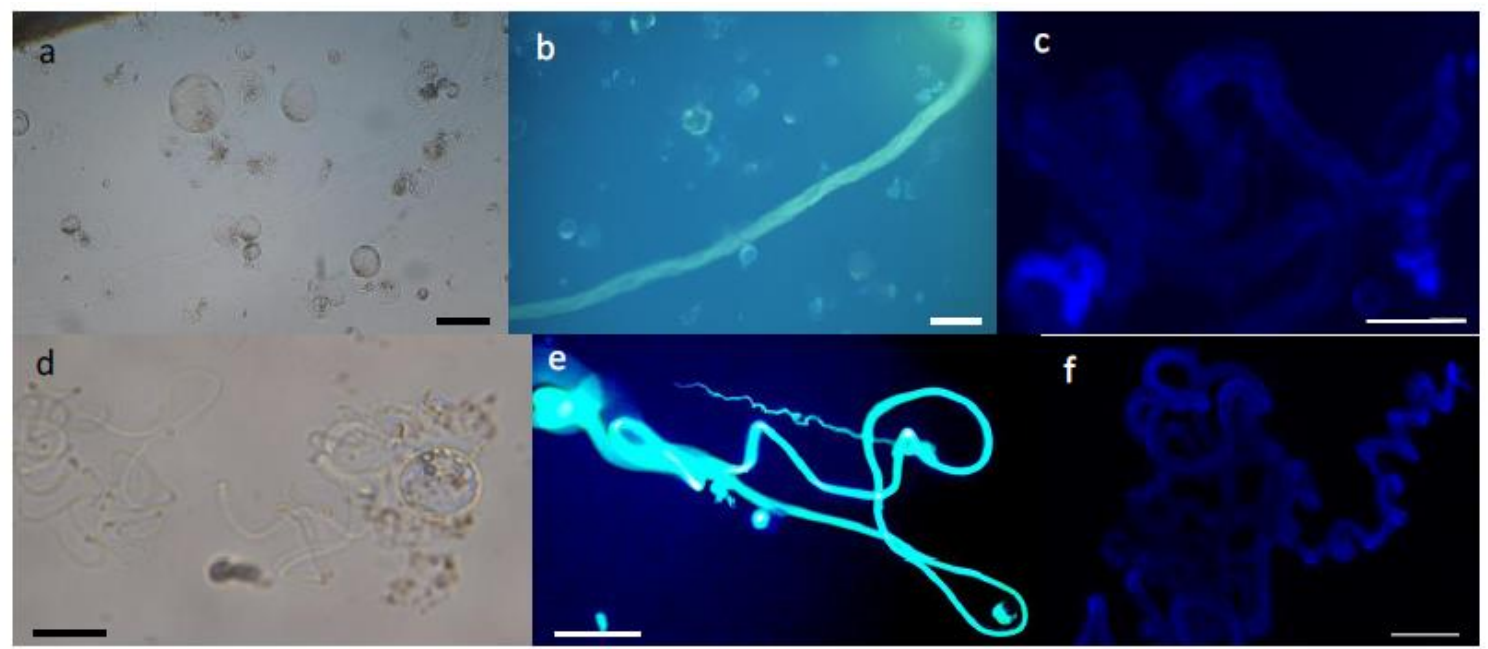

Figure 2. Protoplast-fibers of Avicennia alba (a, b, c) and of Bruguiera sexangula (d, e, f). Phtographed under an inverted microscope (a,d), a fluorescent microscope (b, e) and LCSM (c, f). Bar= $50 \mu \mathrm{m}(\mathrm{a}-\mathrm{e})$ and $10 \mu \mathrm{m}(\mathrm{f})$

Therefore, divalent cations, $\mathrm{Mg}^{2+}$ or $\mathrm{Ca}^{2+}$, and acidic $\mathrm{pHs}$ were not effective for protoplast-fiber formation of halophilic (A. alba) and salt-tolerant (B. sexangula) mangrove plant cells, in this report. There was no inverse relationship between the effects of salts on cell division and protoplast-fiber formation in protoplast cultures of different plant species.

\subsection{Effects of Electric Treatment on Fiber Formation of B. sexangula Protoplasts}

Figure 3 shows the effects of electric treatment $(\mathrm{AC}+\mathrm{DC})$ on protoplast-fiber formation in B. sexangula counted after 5 days of culture. A protoplast with fiber formation was observed under an inverted microscope (Figure 2d). Treatment of AC alone or DC alone and culture without or with $25 \mathrm{mM} \mathrm{MgCl}$, which was slightly stimulatory for cell division (Fukumoto et al., 2004), were not effective for fiber formation (data not shown). Though DC pulse treatment was effective for incorporation of non-permeable fluorescent dye, Allexafluor 488 phalloidin (Oyanagi et al., 2014) and for transformation with a GFP-gene in Larix and B. sexangula protoplasts (Kurita et al., 2008, 2009; Oyanagi et al., 2011, 2014). In contrast, AC plus DC treatment was stimulatory for protoplast-fiber formation in B. sexangula. The electric treatment $(\mathrm{AC}+\mathrm{DC})$ was done using the same condition as that used for cell fusion of poplar protoplasts (Sasamoto et al., 2000), and for interfamilial cell fusion (Wakita et al., 2005). Under the same electric conditions, though cell division and plant regeneration were successful, fibers were not formed from poplar protoplasts (Fukumoto, 2006).

One day storage of the protoplast suspension of B. sexangula before electric treatment was effective for fiber formation (5 times, Figure 3). In this study, we used 3-week-old suspension cultured cells of B. sexangula for protoplast isolation and culture. Although protoplasts could also be isolated from 2-week-old suspension cultured cells, they showed less fiber formation, and higher allelopathic activity than 3-week-old cells using protoplast co-culture method (Mori et al., 2012; Sasamoto et al., 2013). These findings suggested that physiological changes in suspension cells of $B$. sexangula after a longer sub-culture period might be related to the rapid protoplast-fiber formation.

Fiber-forming protoplasts of B. sexangula can be observed after 1-2 days of culture at earliest, which is the most rapid among reported protoplast-fiber forming plant species, such as Larix or Betula, which require 1-2 weeks to one month or more culture for fiber formation. Highly coiled Larix protoplast-fibers up to $2 \mathrm{~mm}$ in length were reported (Sasamoto et al., 2003). However, very long elongated protoplast-fibers of B. sexangula were not recognized after long period of culture. 


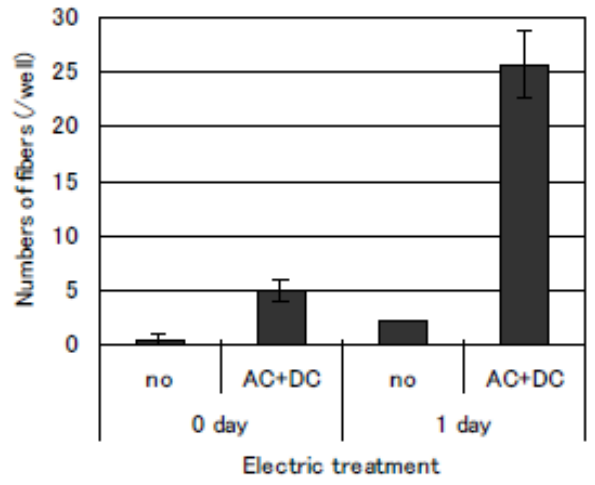

Figure 3. Effects of electric treatment (AC + DC) on fiber formation of Bruguiera sexangula at 0 day or 1 day after isolation of protoplasts. Protoplasts were cultured for 5 days in the MS basal medium containing $0.02 \mu \mathrm{M}$ 2,4-D and $2 \mu \mathrm{M} \mathrm{CPPU}, 3 \%$ sucrose, $0.3 \mathrm{M}$ mannitol and $25 \mathrm{mM} \mathrm{MgCl}_{2}$

\subsection{Callose Staining of Protoplast-Fibers with Aniline Blue and LCSM}

Under an inverted microscope, the protoplast-fiber of A. alba (Figure 2a) was thick and that of B. sexangula (Figure 2d) was thin. The helical structure was not prominent in the A. alba fiber compared with the $B$. sexangula fiber and other previously reported fibers of Betula and Larix (Sasamoto et al., 2003; Fukumoto et al., 2005). Development of thick protoplast-fibers in A. alba and Betula might require a long period (one month or more) of culture.

Protoplast-fibers of two mangrove species, A. alba (Figure 2b) and B. sexangula (Figure 2e) were stained with Aniline Blue and observed under a fluorescence inverted microscope. The blue-green color which was specific for callose was observed in both fibers. Under the strong UV light intensity, fibers moved and the helical structure was loosened. From the LCSM images of $A$. alba (Figure 2c) and B. sexangula (Figure 2f), the diameter of $A$. alba fiber was $15 \mu \mathrm{m}$ and that of $B$. sexangula fiber was $2 \mu \mathrm{m}$, respectively. Image $\mathrm{J}$ analysis was performed for each LCSM image, and diameters of fibril-structures were calculated (Table 1). In the A. alba fiber, a 2-3 fibril structure was recognized and 2 fibrils were observed in the B. sexangula fiber.

Table 1. Size (diameters) of fibrils and sub-fibrils structures of protoplast-fibers in two mangrove species, Avicennia alba and Bruguiera sexangula

\begin{tabular}{lcl}
\hline Protoplast-fiber & A. alba $(\mu \mathrm{m})$ & B. sexangula $(\mu \mathrm{m})$ \\
\hline LCSM & 15 & 2 \\
Fibrils & $6.0+-0.83$ & $1.1+-0.10$ \\
AFM & 22 & 4 \\
Fibrils & $5.8+-0.27$ & $0.99+-0.10$ \\
Subfibrils & $1.0+-0.06$ & $0.35+-0.04$ \\
\hline
\end{tabular}

\subsection{Enzymatic Certification of Callose Component of B. sexangula Fiber}

As shown in Figure 4, a protoplast-fiber of B. sexangula was degraded by the $\beta-1,3$-glucan specific enzyme, laminarinase (Figure 4c), but not by the specific cellulase CBH 1 (Figure 4a). Laminarinase did not degrade the bacterial cellulose and cotton cellulose, which were used as the control (Figures 4f, i), but CBH 1 did (Figures 4d, g). The crude enzyme, Meicelase degraded all protoplast-fibers (Figure 4b), bacterial cellulose (Figures 4e) and cotton cellulose (Figure 4h). These results were consistent with those obtained for Larix protoplast-fibers (Fukumoto et al., 2005). The callose component of the protoplast-fiber of B. sexangula was well certified enzymatically. Disappearance of the protoplast-fiber was confirmed by final staining with Aniline Blue.

The specific blue-green color under a fluorescent microscope after Aniline Blue staining can be a criterion of the protoplast-callose-fiber. Observations of helical elongated fibers under an inverted microscope and under a fluorescent microscope after Aniline Blue staining are conventional methods for detecting the callose protoplast-fiber. 

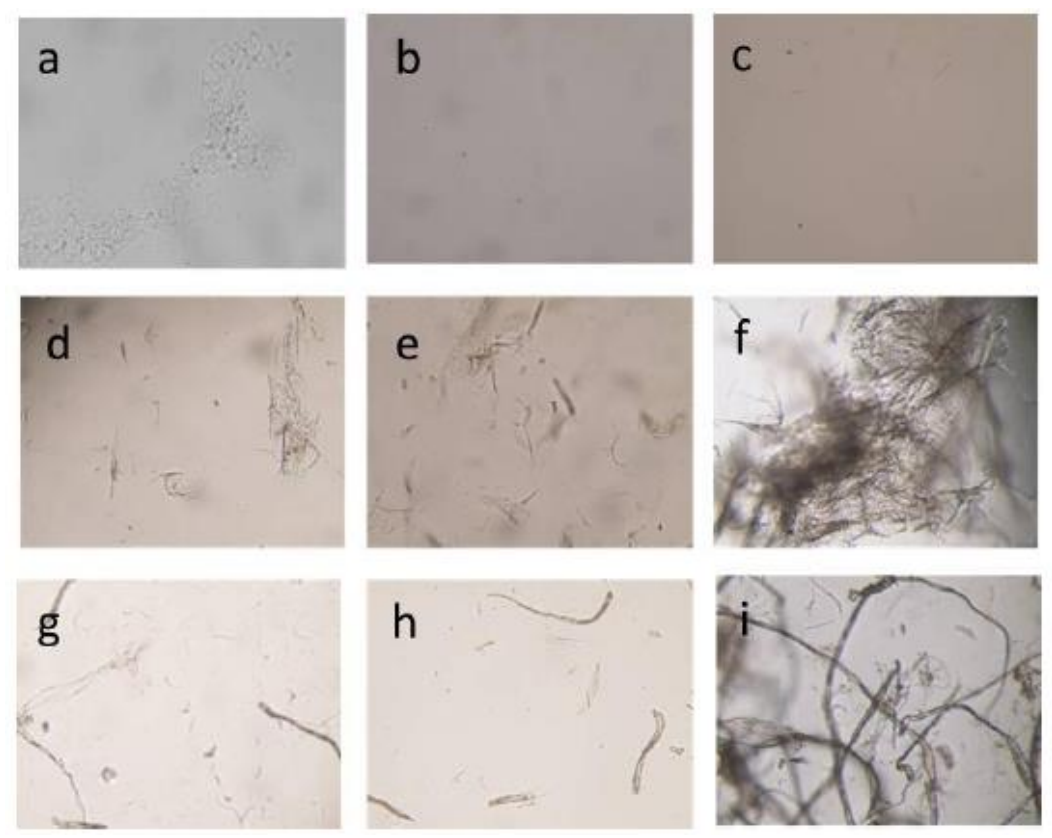

Figure 4. Enzymatic treatment of a protoplast-fiber (a, b, c) of Bruguiera sexangula, bacteria cellulose (d, e, f) and cotton cellulose ( $g, h, i)$ with enzymes CBH1 (a, d, g), Meicelase (b, e, h) and laminarinase (c, f, i).

Photographed under an inverted microscope after 24 hrs incubation

\subsection{Analysis of Substructures of Protoplast-Fibers by AFM and Image $J$}

Figure 5a shows an AFM image of a protoplast-fiber of A. alba. Figure $5 \mathrm{~b}$ shows the results of image $\mathrm{J}$ analysis of the yellow line in Figure 5a. As described in Table 1, diameters of fibril and sub-fibril of the A. alba fiber were calculated to be $5.8 \mu \mathrm{m}$ and $1.0 \mu \mathrm{m}$, respectively. Figure 5c shows an AFM image of protoplast-fiber of $B$. sexangula. Figure 5d shows the results of image $\mathrm{J}$ analysis of dotted line in Figure $5 \mathrm{c}$. Diameters of fibrils and sub-fibrils of the $B$. sexangula fiber were calculated to be $0.99 \mu \mathrm{m}$ and $0.35 \mu \mathrm{m}$, respectively (Table 1). Fibril structures of both fibers are similar to those of LCSM. Though the protoplast-fibers were not homogeneous in size, the $B$. sexangula fiber was smaller than the A. alba fiber.
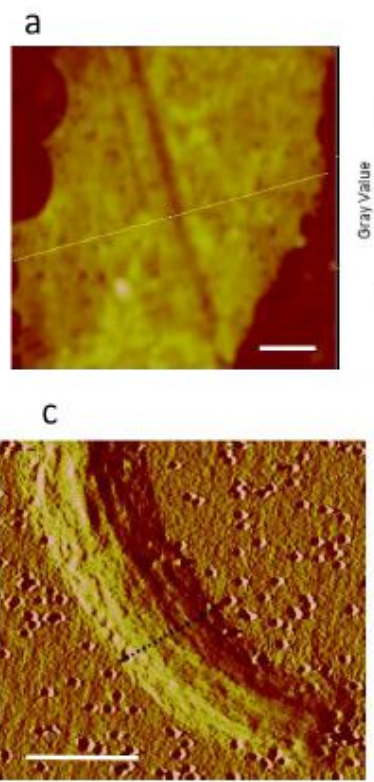

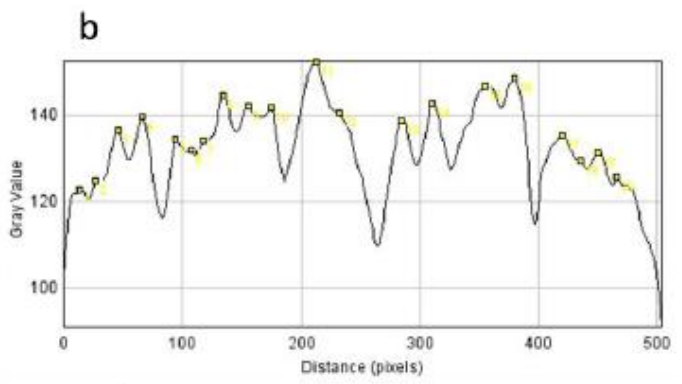

d

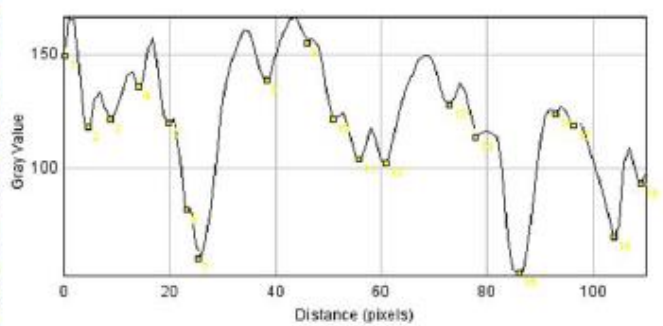

Figure 5. AFM images of protoplast-fibers of Avicennia alba (a) and Bruguiera sexangula (c). b: image J analysis of a yellow line in (a). d: image $\mathrm{J}$ analysis of a dotted line in (c). Bar $=5 \mu \mathrm{m}$ in (a) and (c) 
Conifer Larix fiber and Betula fiber were ca. $10 \mu \mathrm{m}$ and 20-30 $\mu \mathrm{m}$ in diameter, respectively (Sasamoto et al., 2003; Fukumoto et al., 2005; Oyanagi et al., 2014, 2017). Fibril and sub-fibril structures of the Larix protoplast-fiber were calculated to be 0.7 and $0.17 \mu \mathrm{m}$ in diameter, respectively, by AFM and image $\mathrm{J}$ analysis, although the fibril diameter calculated by LCSM and image $\mathrm{J}$ analysis was $0.63 \mu \mathrm{m}$ (Fukumoto et al., 2005; Oyanagi et al., 2014). Fibrils and sub-fibrils of $B$. sexangula were similar in diameter to those of Larix. Fibers and fibrils of $A$. alba were larger than those of $B$. sexangula or Larix. This might be related to the longer culture period of both protoplasts of Betula and A. alba for protoplast-fiber formation.

\subsection{TEM of Protoplast-Fiber of $B$. sexangula}

Tube-like fine structures of $B$. sexangula fiber were clearly observed using TEM (Figure 6). Several protoplasts with elongated fibers were picked up into agarose beads using a micromanipulator, before fixation with glutaraldehyde and processed for TEM. Such a method was first planned to visualize a specific site of fiber elongation on the surface of a single protoplast as in the Larix protoplast-fiber (Oyanagi et al., 2014). However, the TEM images of $B$. sexangula in Figure 6 might be the sub-fibril structures of the fiber itself without protoplasts. Protoplasts are easily separated from the fibers.

Fibers of Larix without fixation selected using a micromanipulator, showed a helical filamentous structure by TEM (Sasamoto et al., 2003).

Recently, dividing protoplasts showing very rapid formation of protoplast-fibers were observed in protoplast culture of another mangrove, Sonneratia caseolaris (Oyanagi et al., 2012a, b), whose suspension cells were less salt-tolerant compared to halophilic suspension cells of S. alba (Hasegawa et al., 2014). It may be possible to clarify the site of fiber elongation from living dividing protoplasts.
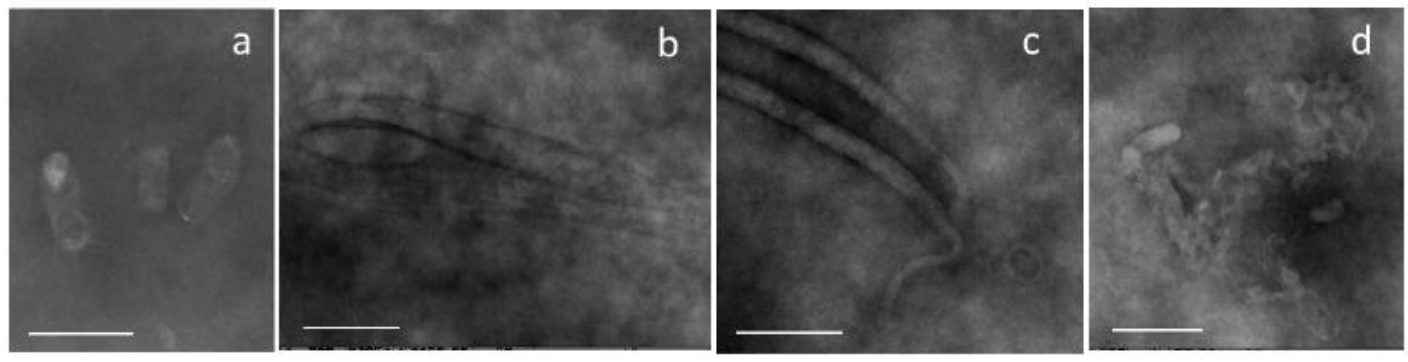

Figure 6. TEM images of protoplast-fiber of Bruguiera sexangula. Bar $=2 \mu \mathrm{m}$

\section{Conclusion}

High concentrations of divalent cations $\mathrm{Mg}^{2+}$ and $\mathrm{Ca}^{2+}$, which are factors of protoplast-callose-fiber formation in non-mangrove tree species, Larix and Betula, were not effective for protoplast-fiber formation in the halophilic mangrove plant, A. alba and salt-tolerant mangrove plant, B. sexangula. In the former A. alba protoplast, addition of a low concentration of $\mathrm{NaCl}$ or without additional salts were effective for formation of protoplast-callose-fiber. In the latter $B$. sexangula protoplasts, though cell division was stimulated by divalent cations, protoplast-fibers were not formed with the salts. Thus, the cationic ions effective for stimulating fiber formation varied with plant species. An inverse relationship was not observed between stimulatory ions for cell division and fiber formation.

Protoplast-fibers of B. sexangula elongated rapidly after 5 days of culture by another new factor, electric cell fusion treatment (AC plus DC) of protoplasts.

The callose component was confirmed under a fluorescent microscope and LCSM in all the protoplast-fibers after Aniline Blue staining, with specific enzymatic degradation by laminalinase, as compared with the lack of degradation by cellulase CBH1.

Sub-structures (fibrils and sub-fibrils) of protoplast-fibers of two mangrove species were investigated by LCSM, AFM and Image $J$ analysis. Diameters of protoplast-fibers were 15-22 $\mu \mathrm{m}$ in A. alba and 2-4 $\mu \mathrm{m}$ in B. sexangula. Fibrils in fibers observed by LCSM were similar in size to those observed by AFM. Fibrils in B. sexangula fibers were similar in size to those of Larix fibers and to those of sub-fibrils of A. alba fibers.

The tube-like fine structures of protoplast-fibers of $B$. sexangula selected using a micromanipulator were observed by TEM. 


\section{References}

Fukumoto, T. (2006). Analysis of novel callose fiber structures and control of their development in plant protoplast cultures. Ph.D. thesis of Yokohama National University. p. 115.

Fukumoto, T., Nakamura, T., Suzuki, M., Ogita, S., Mimura, T., \& Sasamoto, H. (2004). Different effects of four salts and $\mathrm{pHs}$ on protoplast cultures of a mangrove, Bruguiera sexangula suspension cells, Populus alba leaves and tobacco BY-2 cells. Plant Biotechnology, 21, 177-182. http://dx.doi.org/10.5511/plantbiotechnology.21.177

Fukumoto, T., Hayashi, N., \& Sasamoto, H. (2005). Atomic force microscopy and laser confocal scanning microscopy analysis of callose fibers developed from protoplasts of embryogenic cells of a conifer. Planta, 223, 40-45. http://dx.doi.org/10.1007/s00425-005-0065-3

Hasegawa, A., Hayashi, S., Kurita, A., Kaai, F., Kawana, Y., Fukumoto, T., \& Sasamoto, H. (2011). Stimulatory and inhibitory effects of abscisic acid on cell growth in protoplast cultures and the relation to its endogenous levels in Avicenniaceae mangrove cells. Mangrove Science, 8, 11-18.

Hasegawa, A., Kurita, A., Hayashi, S., Fukumoto, T., \& Sasamoto, H. (2013). Halophilic and salts tolerant protoplast cultures of mangrove plants, Sonneratia alba and Avicennia alba. Plant Biotechnology Reports, 7, 205-209. http://dx.doi.org/10.1007/s11816-012-0251-2

Hasegawa, A., Oyanagi, T., Minagawa, R., Fujii, Y., \& Sasamoto, H. (2014). An inverse relationship between allelopathic activity and salt tolerance in suspension cultures of three mangrove species, Sonneratia alba, $S$. caseolaris and $S$. ovata: development of a bioassay method for allelopathy, the protoplast co-culture method. Journal of Plant Research, 127, 755-761. http://dx.doi.org/10.1007/s10265-014-0651-1

Hayashi, N., Sugiyama, J., Okano, T., Ishihara, M., \& Shimizu, K. (1997a). Selective degradation of cellulose Ia component in Cladophora cellulose with Trichoderma viride cellulase. Carbohydrate Research, 305, 109-116. http://dx.doi.org/10.1016/S0008-6215(97)00281-4

Hayashi, N., Sugiyama, J., Okano, T., Ishihara, M., \& Shimizu, K. (1997b). The enzymatic susceptibility of cellulose microfibrils of the algal-bacterial type and the cotton-ramie type. Carbohydrate Research, 305, 261-269. http://dx.doi.org/10.1016/S0008-6215(97)10032-5

Hayashi, S., Kuriyama, S., Kawana, Y., Hasegawa, A., Kurita, A., Minagawa, R., \& Sasamoto, H. (2009). Stimulatory effects of sea salts on cell growth in liquid culture of Avicenniaceae mangrove. Plant Biotechnology, 26, 561-564. http://dx.doi.org/10.5511/plantbiotechnology.26.561

Kura-Hotta, M., Mimura, M., Tsujimura, T., Nemoto-Washitani, S., \& Mimura, T. (2001). High salt treatment-induced $\mathrm{Na}+$ extrusion and low salt treatment-induced $\mathrm{Na}+$ accumulation in suspension-cultured cells of the mangrove plant, Bruguiera sexangula. Plant, Cell \& Environment, 24, 1105-1112. http://dx.doi.org/10.1046/j.0016-8025.2001.00761.x

Kurita, A., Hasegawa, A., Hayashi, N., \& Sasamoto, H. (2008). Novel Callose fiber formation developed in protoplast cultures of a mangrove plant. Proceedings of the 72th Annual Meeting of the Botanical Society of Japan, p. 233.

Kurita, A., Fukumoto, T., Hayashi, N., Shiraishi, T., \& Sasamoto, H. (2009). Characteristics of novel elongated callose fiber and regulatory mechanisms of the fiber formation in tree protoplast cultures: Mechanical properties; AFM; LCSM; TEM; GFP gene transformation. Proceedings of the 59th Annual Meeting of the Japan Wood Research Society, p. 96.

Mimura, T., Mimura, M., Washitani-Nemoto, S., Sakano, K., Shimmen, T., \& Siripatanadilok, S. (1997). Efficient callus initiation from leaf of mangrove plant, Bruguiera sexangula in amino acid medium: effect of $\mathrm{NaCl}$ on callus initiation. Journal of Plant Research, 110, 25-29. http://dx.doi.org/10.1007/BF02506839

Murashige, T., \& Skoog, F. (1962). A revised medium for rapid growth and bioassay with tobacco tissue cultures. Physiologia Plantarum, 15, 473-497. http://dx.doi.org/10.1111/j.1399-3054.1962.tb08052.x

Mori, D., Hasegawa, A., Fukumoto, T., Watanabe, S., \& Sasamoto, H., (2012). Bioassay of allelopathy using protoplast co-culture method in Bruguiera sexangula and Kandelia obovata. Abstracts of 18th annual meeting of Japanese mangrove society, p 17.

Ogita, S., Sasamoto, H., \& Kubo, T. (1999). Selection and microculture of single embryogenic cell clusters in Japanese conifers: Picea jezoensis, Larix leptolepis and Cryptomeria japonica. In Vitro Cellular and Developmental Biology Plant, 35, 428-431. http://dx.doi.org/10.1007/s11627-999-0061-6 
Oyanagi, T., Hayashi, N., Kurita, A., Fukumoto, T., \& Sasamoto, H. (2011). Fine structures of the site of callose-fiber formation from protoplast cultures of tree plants: Single cell TEM, LCSM, GFP gene transformation. Proceedings of the 61th Annual Meeting of the Japan Wood Research Society, p. 103.

Oyanagi, T., Hasegawa, A., Sasamoto, H., Hayashi, N., \& Fukumoto, T. (2012a). Cell divisions and callose fiber formation in cultures of protoplasts isolated from suspension cells of a mangrove plant, Sonneratia caseolaris. Proceedings of the 62th Annual Meeting of the Japan Wood Research Society, p. 116.

Oyanagi, T., Hasegawa, A., Fukumoto, T., \& Sasamoto, H. (2012b). Control of Novel callose fiber formation and cell divisions in protoplast culture of Sonneratia caseolaris. Abstracts of 18th annual meeting of Japanese mangrove society, $\mathrm{p} 16$.

Oyanagi, T., Kurita, A., Fukumoto, T., Hayashi, N., \& Sasamoto, H. (2014). Laser confocal scanning microscopy and transmission electron microscopy to visualize the site of callose fiber elongation on a single conifer protoplast selected with a micromanipulator. Journal of Plant Studies, 3, 23-29. http://dx.doi.org/10.5539/jps.v3n2p23

Oyanagi, T., Kurita, A., Shiraishi, T., \& Sasamoto, H. (2017). Development of a method to measure mechanical properties of single elongated callose fibers in protoplast cultures of Larix leptolepis and Betula platyphylla. Journal of Plant Studies, 6, 31-38. http://dx.doi.org/10.5539/jps.v6n1p31

Rasband, W. S. (1997-2016). Image J. U. S. National Institute of Health, Bethesda, Maryland, USA. Retrieved from http://imagej.nih.gov/ij

Sasamoto, H., Wakita, Y., Yokota, S., \& Yoshizawa, N. (2000). Large electro-fused protoplasts of Populus alba selected by a micromanipulator: Techniques and some characteristics of cells and their regenerants. Journal of Forest Research, 5, 265-270. http://dx.doi.org/10.1007/BF02767120

Sasamoto, H., Ogita, S., Hayashi, N., Wakita, Y., Yokota, S., \& Yoshizawa, N. (2003). Development of novel elongated fiber-structure in protoplast cultures of Betula platyphylla and Larix leptolepis. In Vitro Cellular and Developmental Biology Plant, 39, 223-228. http://dx.doi.org/10.1079/IVP2002388

Sasamoto, H., Murashige-Baba, T., Inoue, A., Sato, T., Hayashi, S., \& Hasegawa, A. (2013). Development of a new method for bioassay of allelopathy using protoplasts of a leguminous plant Mucuna pruriens with a high content of the allelochemical L-DOPA. Journal of Plant Studies, 2, 71-80. https://doi.org/10.5539/jps.v2n2p71

Seyama, T., Kimura, S., Sasamoto, H., Abe, H., \& Kondo, T. (2008). Spinning of a gigantic bundle of hollow fibrils by a spirally moving higher plant protoplast. Planta, 227, 1187-1197. http://dx.doi.org/10.1007/s00425-008-0689-1

Tagawa, S., \& Kondo, T. (2018). Secretion of a callose hollow fiber from herbaceous plant protoplasts induced by inhibition of cell wall formation. Journal of Wood Science, 64, 467-476. https://doi.org/10.1007//s10086-018-1726-8

Wakita, Y., Yokota, S., Yoshizawa, N., Katsuki, T., Nishiyama, Y., Yokoyama, T., Fukui, M., \& Sasamoto, H. (2005). Interfamilial cell fusion among leaf protoplasts of Populus alba, Betula platyphylla and Alnus firma: assessment of electric treatment and in vitro culture conditions. Plant Cell, Tissue and Organ Culture, 83, 319-326. http://dx.doi.org/10.1007/s11240-005-8428-9

\section{Copyrights}

Copyright for this article is retained by the author(s), with first publication rights granted to the journal.

This is an open-access article distributed under the terms and conditions of the Creative Commons Attribution license (http://creativecommons.org/licenses/by/4.0/). 